\title{
SISTEM TRANSAKSI FOREX TRADING MENGGUNAKAN METAQUOTES LANGUAGE 4
}

\author{
Uning Lestari ${ }^{1}$ \\ Henderi $^{2}$ \\ e-mail : uning-lestari@yahoo.co.id, henderi@yahoo.com
}

Diterima : 20 Desember 2011/ Disetujui : 26 Desember 2011

\begin{abstract}
Now a lot of online businesses is on offer on the internet, particularly in the field of business Forex Online Trading. Lots of software that is used by traders for trading such as FX Clearing. FX Clearing is a software that is often used to trade forex traders in particular that uses a mini account. However, traders often have floating lost in trading it is because emotions are not controlled by the traders themselves. One solution to solve this problem so that traders do not always have floating lost is using Expert Advisors, Expert Advisors are applications that traders use to trade automatically without monitor price movements for 24 hours of the usual traders in general. Expert Advisors designed using the $C$ programming language in the platform MetaQuotes Language4 (MQL4). So expect the use of Expert Advisors can facilitates for traders to trade without having to monitor price movements for 24 hours, and is expected to be the desired profit without having lost a very significant, because it has particularly Expert advisors to the ability of otomats trading, trading without emotion, and the nonstop 24 hour trading capabilities.
\end{abstract}

Keywords: Trader, Trading, Expert Advisors

\begin{abstract}
Sekarang ini banyak bisnis online yang ditawarkan di internet, khususnya bisnis dalam bidang Forex Online Trading. Banyak sekali software-software yang digunakan oleh trader
\end{abstract}

1. Dosen Jurusan Teknik Informatika, Institut Sains \& Teknologi AKPRIND Yogyakarta

Jl. Kalisahak No. 28 Komplek Balapan Yogyakarta 55222.

2. Dosen Jurusan Teknik Informatika, STMIK Raharja

Jl. Jend Sudirman No. 40 Modern Cikokol-Tangerang Telp. 5529692 
untuk trading seperti FX Clearing, FX Clearing merupakan software yang sering digunakan trader dalam bertransaksi forex khususnya yang menggunakan account mini. Akan tetapi trader sering sekali mengalamin floating lost dalam trading itu dikarenakan emosi yang tidak terkontrol oleh trader itu sendiri. Salah satu solusi untuk mengatasi masalah ini agar trader tidak selalu mengalami floating lost adalah dengan menggunakan Expert Advisors, Expert Advisors adalah aplikasi yang digunakan trader untuk trading secara otomatis tanpa memantau pergerakan harga selama 24 jam yang biasa dilakukan trader pada umumnya. Expert Advisors dirancang menggunakan bahasa pemrograman $C$ di dalam platform MetaQuotes Language4 (MQL4). Sehingga diharapkan pada penggunaan Expert Advisors dapat memberi kemudahan bagi trader dalam trading tanpa harus memantau pergerakan harga selama 24 jam, dan diharapkan dapat profit yang diinginkan tanpa mengalami lost yang begitu signifikan, dikarenakan Expert advisors ini meiliki kemampuan untuk trading secara otomats, trading tanpa emosi, dan kemampuan trading nonstop 24 jam.

Kata Kunci : Trader, Trading, Expert Advisors

\section{PENDAHULUAN}

Dalam beberapa dekade terakhir ini banyak sekali bisnis online yang ditawarkan di internet yang tersebar diseluruh dunia baik individu maupun perusahaan mulai terjun di dunia bisnis online khususnya bisnis online yang melakukan transaksi produk komoditi berjangaka dengan cara online trading baik dalam hal Index saham, maupun Forex (FX), dalam hal ini dikhususkan Forex Online Trading. Valuta Asing adalah pasar mata uang dimana satu perdagangan terhadap mata uang lain berlangsung. Hal ini sering disebut sebagai Forex atau FX. Di pasar valuta asing adalah pasar terbesar dan paling likuid pasar paling berpengaruh di dunia. Ini adalah benar-benar 24 jam pasar global, maka perdagangan dari 9 GMT Minggu sampai 10 GMT Jumat dan perdagangan lebih dari \$ 3 triliun dolar sehari, membuat itu jauh lebih besar dari gabungan total semua bursa saham dunia.

Dalam bertransaksi seseorang yang akan melakukan transaksi atau yang biasa disebut Trader sebelum mengambil keputusan untuk masuk pasar, maka trader tersebut menganalisa pasar terlebih dahulu, jika sudah benar-benar yakin untuk masuk pasar baik akan mengambil posisi buy atau sell baru trader akan melakukan transaksi, Akan tetapi walau bagaimanapun seorang trader tetaplah manusia biasa, sehingga trader tersebut terkadang tidak bisa mengontrol emosinya dan cendrung serakah dalam melakukan transakasi sehingga trader berharap akan mendapatkan keuntungan atau profit akan tetapi yang terjadi adalah malah sebaliknya trader mengalami floating lost. Oleh karena itu untuk memanajemen resiko floating lost 
dan mendapatkan profit dalam trading online seorang trader membutuhkan robot forex atau biasa disebut Expert Advisors untuk transaksi secara otomatis.

Berdasarkan latar belakang permasalahan di atas, maka yang akan dibahas dalam penelitian ini mengenai pembuatan Expert Advisors di dalam platform MQL4 (MetaQuotes Language Version4) sebagai transaksi forex online trading secara otomatis yang nantinya akan di terapkan pada FX Clearing. Expert Advisors tersebut akan menggantikan tugas dari trader untuk trading, Expert Advisors nantinya akan bekerja sebagai mana yang biasa dikerjakan trader pada umumya dengan menganalisa pasar melalui indikator yang dihasilkan candle stick lalu masuk pasar untuk melakukan open order atau close order.

Yang membedakan adalah Expert Advisors akan melakukan transakasi secara otomatis dan bisa bekerja selama 24 jam nonstop, selain itu Expert Advisors ini akan melakukan transaksi dengan menganalisa pasar terlebih dahulu dengan mengacu pada tiga indikator, yaitu Heiken Ashi indikator, Momentum indikator, Avarege Tru Range Indikator dan pivot point sebagai pematok trend harga yang akan terjadi, tidak seperti Expert advisors sebelumnya yang hanya mengandalkan satu indikator atau bahkan tanpa indikator. Sehingga Expert Advisors akan melakukan transaksi jika ketiga indikator tersebut benar-benar valid. Hal ini dapat mempermudah trader dalam mengambil keputusan dalam melakukan trading atau transaksi forex dengan keuntungan yang diinginkan. Dengan demikian dapat mempermudah trader dalam mengambil keputusan dalam melakukan trading atau transaksi di dalam produk komoditi berjangka produk yang berupa nilai mata uang asing yang disebut forex.

\section{TINJAUAN PUSTAKA}

Penelitian Expert Advisors telah dilakukan oleh (Abiyanto) yang membuat Expert Advisors tanpa indikator, dalam penelitian ini memiliki kelemahan bahwa Expert Advisors tersebut melakukan transaksi yang tanpa terkontrol dengan baik, karena sistem kerja Expert Advisors yang tanpa analisa yang dihasilkan oleh indikator. (Abiyanto, http://www.abiyanto.net/?page_id=180 ) Dari penelitaian Expert Advisors sebelumnya pada penelitian kali ini dicoba untuk dikembangkannya Expert Advisors yang akan mengacu kepada indikator-indikator yang dihasilkan sebagai analisa teknikal untuk masuk dan keluar dari pasar.

Selain dari penelelitian (Abiyanto) pembuatan Expert Advisors ini juga merupakan pengembangan dari penelitian yang dilakukan oleh (Sumitar) mengenai Expert Advisors PyramidEA Ultimate Jika dalam penelitian yang dilakukan Simitar mengembangkan expert advisors PyramidEA Ultimate yang hanya mengacu pada Indikator MACD (Moving Average Convergence / Divergence), maka dalam 
penelitian kali ini mencoba membuat Expert Advisors yang mengacu pada indikator Momentum, Heinken Ashi dan Avarege Tru Range dengan Pivot indikator sebagai pematok harga dari trend yang akan terjadi, serta Expert Advisor yang dapat di implementasikan terhadap FX Clearing. (Sumitar, http://www.sumintar.com/ category/forex )

\section{Forex Online Trading}

Foreign Exchange (Forex) adalah proses membeli nilai suatu mata uang untuk kemudian dijual (ditukarkan) ke mata uang lainnya dalam waktu yang bersamaan. (Sawidji Widoatmojo,2008, ) Forex merupakan pasar perdagangan yang dikenal luas dengan sebutan valas dimana melibatkan jenis perdagangan uang antar negara selama 24 jam penuh. Dalam volatilitas pergerakan mata uang yang tinggi, pihak individu maupun korporasi dapat mengambil keuntungan dari fluktuasi tersebut, serta resiko yang dapat dikendalikan dengan manajemen resiko yang ada. Dengan kemampuan investor untuk tetap bertransaksi bebas dari tuntutan jam perdagangan, investor dapat leluasa menentukan jam-jam perdagangan maupun ketika memutuskan untuk keluar dari pasar.

Perdagangan forex adalah perdagangan paling likuid dimana selalu terdapat pembeli dan penjual, perdagangan forex menawarkan kesempatan untuk mengambil posisi beli dan jual di pasar. Pasangan mata uang misalnya Euro terhadap US Dollar, US Dollar terhadap Yen, Poundsterling terhadap US Dollar, serta beberapa mata uang kombinasi lainnya.

\section{Mekanisme Transaksi Forex}

Mekanisme trasaksi Forex Online Trading adalah dengan melihat trend yang dihasilkan oleh indikator, pada saat trend naik, trader mulai dengan posisi Buy dahulu, lalu ditutup dengan posisi Sell. Pada saat trend turun, mulai posisi Sell dahulu, ditutup dengan posisi Buy. Pada prinsipnya transaksi Forex juga bisa dilakaukan dengan transaksi dua arah dimana bisa mengambil posisi Buy maupun Sell secara bersamaan. Bila diprediksi harga saham akan turun, Sell New dan setelah itu Buy Liquid. Bila diprediksi harga saham akan naik $\underline{B u y ~ N e w}$ dan kemudian Sell Liquid . Secara garis besar mekanisme transaksi ini dengan cara memantau pergerakan harga pasar, dengan tetap mengacu pada trend harga yang dihasilkan oleh indikator-indikator yang digunakan. Pada saat trend naik, dimulai posisi buy dahulu, lalu ditutup dengan posisi sell apabila telah mendapatkan profit atau keuntungan. Pada saat trend turun, dimulai posisi sell dahulu, lalu ditutup dengan posisi buy. Bila telah mendapatkan keuntungan atau profit. 


\section{Value per point}

Nilai yang diperoleh dalam Point dalam forex.

\section{POINT : Rp 10.000,- (Sepuluh Ribu Rupiah)}

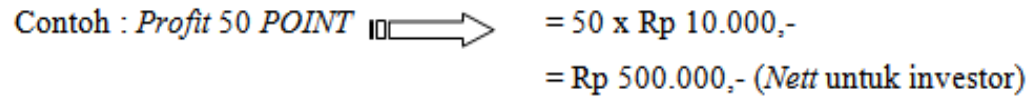

Biaya transaksi

Komisi untuk setiap transaksi /lot dan untuk setiap transaksi dibebankan biaya sebesar :

$>$ Spreed $=3$ POINT

$>$ Comission $=6$ POINT $(+)$

$>B E P \quad=9$ POINT

Keterangan :

Spreed $\longrightarrow$ Nilai Selisih antara Harga JUAL dan BELI

Contoh :

Harga JUAL

Harga BELI

\subsection{0}

Comission
1.9853

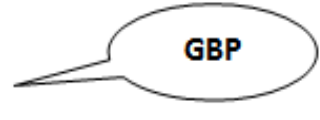

\section{FX Clearing}

FX Clearing adalah suatu software forex online trading yang dikembangkan oleh MetaQuotes Software.Corp yang digunakan untuk bertrading forex secara online,. Software FX Clearing dapat dijalankan di PC, laptop, maupun PDA, dan penggunaan software FX Clearing disarankan dijalankan di system operasi windows agar mempermudah pengoperasiannya.

FX Clearing mempunyai kelebihan hemat bandwidth sehingga meskipun koneksi internet sangat minimpun FX Clearing ini dapat tetap berjalan dengan lancar. Disamping itu kelebihan FX Clearing yaitu dapat dijalankan secara bersamaan dilayar yang berbeda ataupun multi windows ( multi account dan dapat double login) dan sangat flexible dan sangat user friendly sekali.

Kelebihan yang paling terlihat dalam software FX Clearing ini adalah dapat ditambahkannya suatu script yang dimana dapat di program sendiri dan dapat digunakan untuk automatic trading ( Expert Advisor ) yang bisa berjalan dengan skenario trading para trader. Untuk memprogram Expert Advisor ini dapat digunakan sebuah editor khusus yang ada pada software FX Clearing ini yaitu 
Meta Editor, yang terdapat di flat form MQL4 (MetaQuotes Language Version 4). MetaQuotes Language Version4 (MQL4) merupakan bahasa pemrograman yang dikembangkan oleh MetaQuotes Software corp, yang berfungsi sebagai tempat merancang Expert Advisors atau custom indicator yang menggunakan bahasa C. (http://www.docs.mql4.com)

\section{Expert Advisors}

Expert Advisors adalah program untuk mengotomatisi trading berdasarkan logika-logika dan parameter-parameter tertentu., Expert Advisors yang seringkali disebut robot forex dapat melakukan beberapa eksekusi trading secara otomatis dan relatif lebih cepat daripada manusia karena itu fasilitas ini sangat cocok bagi trader yang menginginkan kemudahan dalam trading. (http://www.forexindo.com)

Trader tidak harus memantau pergerakan forex (valas) secara nonstop seperti apa yang umumnya dilakukan trader jika memiliki floating loss. Expert Advisor dapat mengambil alih dalam melakukan open order, close order yang telah profit, cut loss, ataupun money management. Tetapi patut diingat bahwa trader tidak dapat sepenuhnya bergantung terhadap Expert Advisors tanpa mengerti cara, dasar, dan mekanisme trading forex itu sendiri. Peran serta trader sangatlah penting dalam trading menggunakan robot forex, karena timing dan setting yang tepat dalam penggunaan Expert Advisors akan menentukan kesuksesan trader.

\section{Indikator}

Indikator suatu alat bergerak yang berfungsi sebagai petunjuk arah yang memberikan indikasi tentang sesuatu keadaan yang merupakan refleksi dari keadaan tersebut pasar yang sebenarnya. Dalam defenisi lain, indikator dapat dikatakan sebagai variabel penolong dalam mengukur perubahan karena indikator ini akan merajuk kedalam kondisi pasar yang sebenarnya secara real time. Variabel-variabel ini terutama digunakan apabila perubahan yang akan dinilai tidak dapat diukur secara langsung. (http://www.autotradingfx.com/forum/langkah2-sebelum-bikin-ea).

\section{Indikator Heiken Ashi}

Heinken Ashi adalah indikator yang dikembangkan oleh orang jepang Ichimoku Heiken Ashi. Heiken Ashi sendiri terkenal sebagai all in one indikator karena memang dari awalnya dibuat oleh Hosoda (seorang wartawan) untuk memenuhi keinginannya menggunakan satu indikator yang bisa menampilkan semuanya. Heiken Ashi digunakan sebagai alternatif pengganti Candle Stick. Gunanya untuk menghilangkan bias trend dan memperjelas arah trend yang sedang terjadi. 


\section{Indikator Momentum}

Momentum merupakan indicator yang menghitung besarnya perubahan harga suatu produk sekuritas dalam jangka waktu tertentu. Pergerakan indicator Momentum sering kali mendahului pergerakan harga pada waktu terjadi perubahan arah trend dalam perdagangan. Karena itu, indicator Momentum dapat digunakan sebagai indicator dini (leading indicator).

Penggunaan indicator Momentum hampir sama dengan penggunaan indicator Price Rate of Change (ROC). Kedua indicator ini sama-sama menunjukkan laju perubahan dari suatu harga produk. Akan tetapi, indicator Price ROC menunjukkan perubahan harga dalam bentuk persentasisedangkan indicator Momentum menunjukkan perubahan harga dalam bentuk rasio. Indicator Momentum dapat digunakan untuk menunjukkan trend pergerakan naikturun (oscillator) suatu harga. Sinyal beli muncul jika indicator ini berada di bawah dan kemudian naik, sedangkan sinyal beli muncul jika indicator ini berada di atas dan kemudian turun.

\section{PEMBAHASAN}

Sebelum menjalan program perlu dilakukan langkah-langkah sebagai berikut:

\section{* Instalasi Software FX Clearing}

Software FX Clearing dapat dijalankan di PC, Laptop, maupun PDA, dan penggunaan software FX Clearing disarankan dijalankan di system operasi Windows agar mempermudah pengoperasiannya.

\section{* Implementasi Sistem}

Tahap implementasi sistem merupakan tahap meletakkan sistem agar sistem tersebut siap untuk dioperasikan sesuai dengan yang direncanakan. Program harus ditulis dengan baik dan terstruktur agar jika terdapat kesalahan di dalam program atau mungkin karena adanya perubahan sistem yang terpaksa harus mengubah programnya dapat dianalisa dengan mudah. Program ini dikembangkan dengan menggunakan pemrograman C mengunakan Meta Editor Sebagai Text Editor pembuatan program dan MetaTrader di dalam pflatform MQL4, dan diimplementasikan pada sistem operasi Windows XP.

\section{* Analisa Pengujian Sistem}

Untuk memulai pengujian sistem diharuskan membuka account baru agar sistem bisa dijalankan,membuat account demo bisa melalui software FX Clearing, dilakukan langkah-langkah :

1. Proses Pembuatan Account Baru

2. Proses Pemilihan Server

3. User \& Password FX Clearing 
4. Input Account

5. Tampila Halaman Utama FX Clearing

Berikut adalah tampilan halaman utama dari FX Clearing dapat dilihat pada Gambar 1:

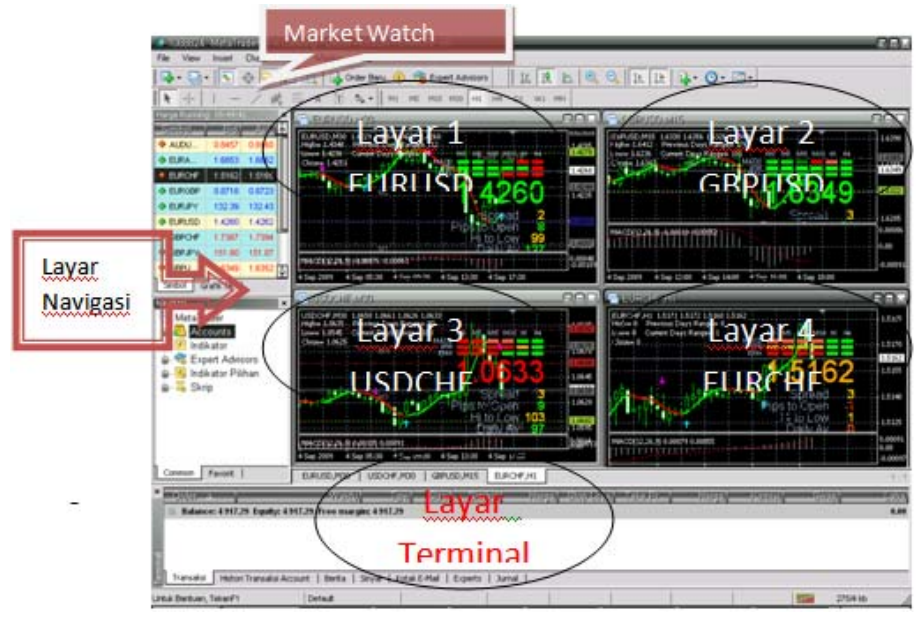

\section{Proses Transakasi Expert Advisors}

* Analisa Transakasi Open Buy

Setelah semua parameter pada strategy tester selesai di setting trader dapat menjalankan Expert Advisors yang akan diuji.

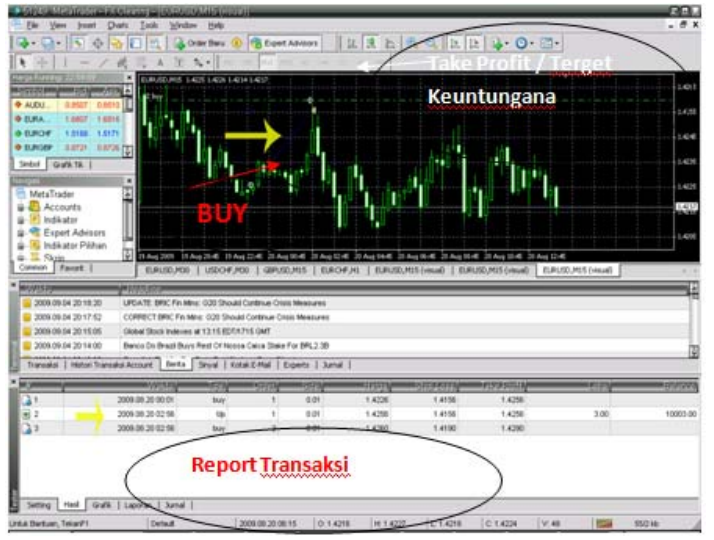

Gambar 2. Open Buy Expert Advisors 
Pada Gambar 2 dijelaskan proses terjadinya transaksi yang dilakukan Expert Advisors dengan order Buy, diharga 1.4226 dan telah mendapatkan Take Profit sebesar 30 pips di harga 1.4256 dengan jumlah transaksi sebesar 0.01 lot.

\section{* Analisa Transakasi Open Sell}

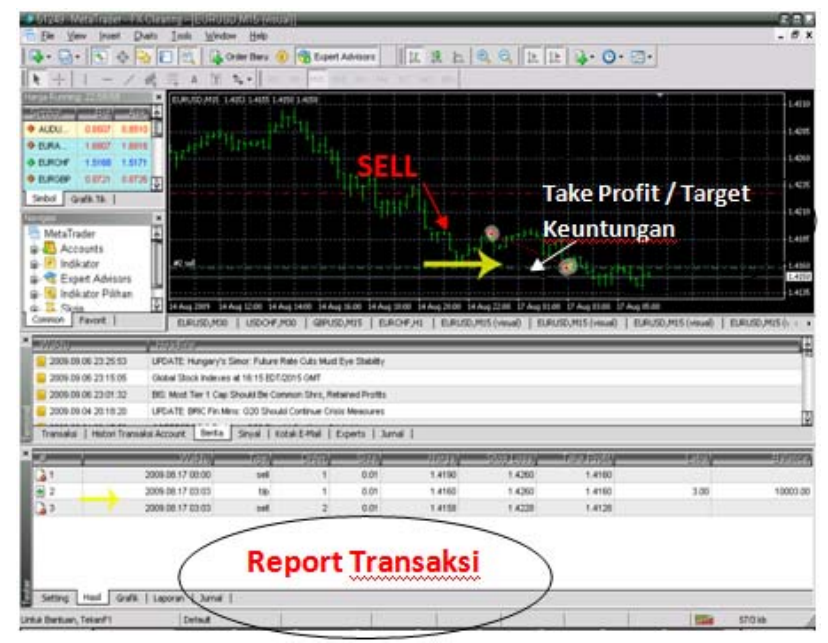

Pada Gambar 3 dijelaskan proses terjadinya transaksi yang dilakukan Expert Advisors dalam melakukan open Sell, transaksi terjadi di level harga 1.4190 dan telah mendapakan Take Profit di harga 1.4160 sebanyak 30 Pips dengan jumlah transaksi 0.01 lot.

\section{Analisa Perbandingan Manual Tarding dan Expert Trading. \\ Manual Trading}

Sebelum mengambil posisi untuk open order biasanya seorang trader menganalisa pergerakan harga yang akan terjadi, apakah harga akan naik atau akan turun, Trader menganalisa pasar biasanya menggunakan indikator-indikator yang mendukung keputusan untuk melakukan transaksi. Banyak indikator-indikator yang dapat digunakan trader untuk menganalisa, tergantung ketertarikan tersendiri. berikut analisa trader dalam melakukan open order maupun close order baik open atau sell.

\section{Cara Melakukan Order}

Untuk melakukan perintah order, trader dapat menekan tombol F9 atau dengan meng-click kanan di layar Market Watch lalu pilih New Order, setelah itu akan muncul layar seperti Gambar 4 : 


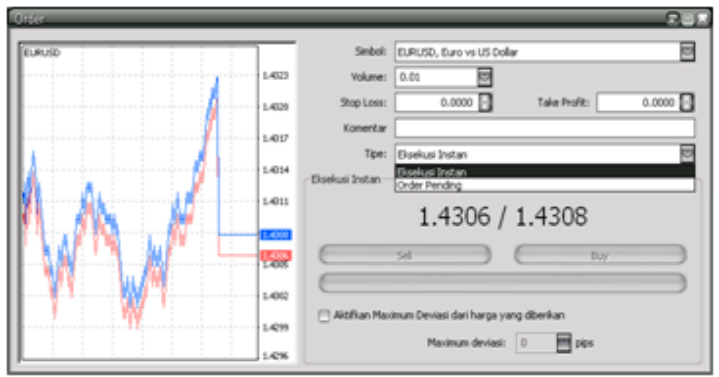

Gambar 4. Open Order

Trader bisa melakukan order dengan Instan Execution (order dengan harga saat sekarang), ataupun dengan Pending Order (order yang akan terlaksana jika menyentuh suatu tutuk harga tertentu yang sebelumnya trader pesan terlebih dahulu). Setelah trader berhasil melakukan order, maka di layar Terminal (di bagian trade) akan muncul seperti Gambar 5:

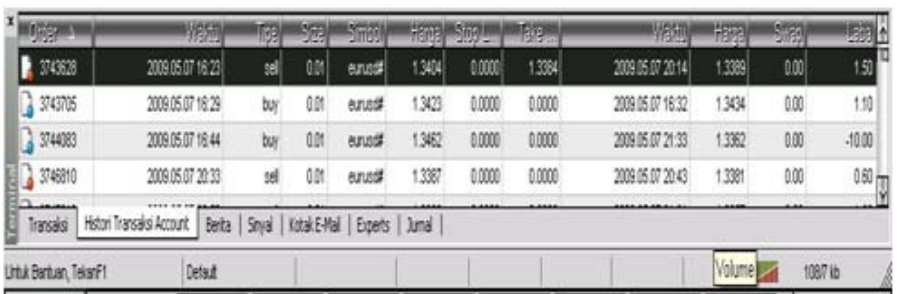

Gambar 5. Transaksi Yang Sedang Berjalan

\section{Modifikasi Order}

Order-order ini bisa trader modifikasi dengan cara click kanan pada posisi order yang ingin trader rubah ataupun ingin sett perintah trailing stopnya dapat dilihat pada Gambar 6.

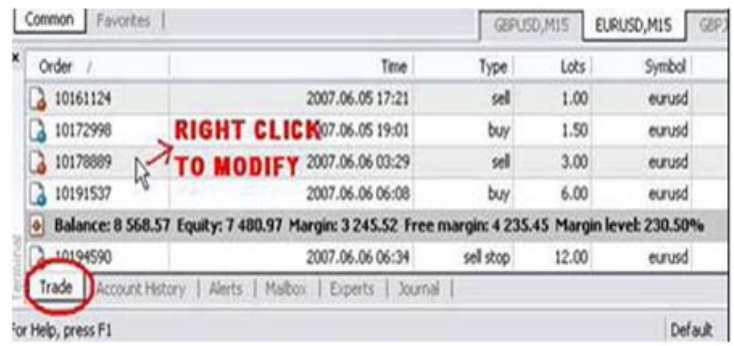

Gambar 6. Modifikasi Trading 


\section{Expert Advisors Trading}

Expert Advisors dirancang khusus menggunakan MQL4 yang mendukung bahasa pemrograman C, untuk memudahkan trader dalam bertransaksi forex. Selain itu trader juga tidak harus menganalisa pergerakan harga yang akan terjadi melalui indikator-indikator yang biasa digunakan, karena tugas seorang trader telah digantikan oleh Expert Advisors yang telah di program khusus dengan indikator untuk melakukan transaksi. Untuk menjalankan Expert Advisors trader dapat mengklik tombol Play dan Stop yang terdapat pada menu bar atas di tampilan utama FX Clearing pada Gambar 7
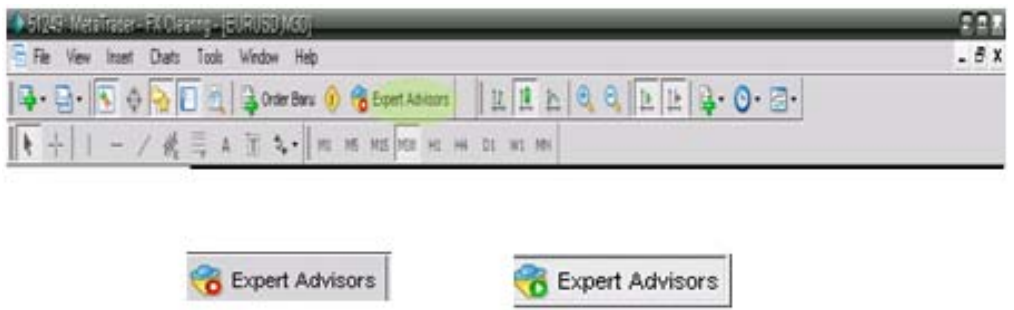

Gambar 7 . Menjalankan Expert Advisors

Setelah Expert Advisors dijalankan, otomatis akan melakkukan transaksi berdasarkan yang diperintahkan pada source program. Expert Advisors akan otomatis order Buy jika harga pasar akan naik, dan otomatis Sell jika harga yang ditawarkan akan turun. Apabila belum mencapai target maka Expert Advisors akan otomatis modifikasi order sampai memenuhi target yang dicapai, dan jika target telah dicapai oleh Expert Advisors maka akan otomatis close order . Hal tersebut dapat dilihat pada Gambar 11.

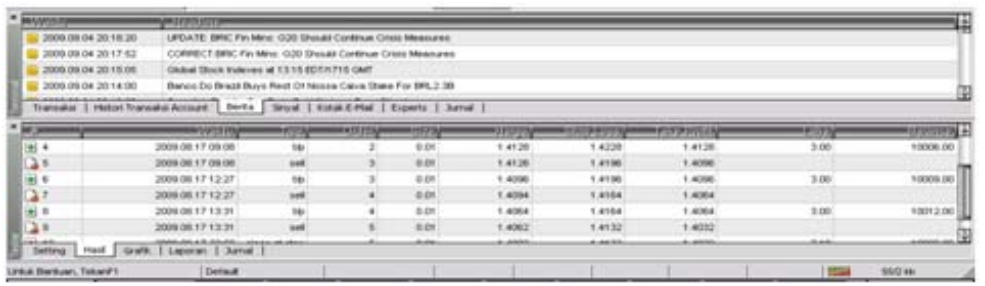

Gambar 11. Transaksi yang dilakukan Expert Advisors

\section{Hasil Transaksi Manual Trading \& Expert Trading Report Manual Trading}

Hasil transaksi trader menggunakan manual trading, data diambil kisaran tanggal (17-08-2010 s/d 22-08-2010) selama satu minggu . Pada Gambar 12 
dapat dijelaskan bahwa transaksi forex online trading menggunakan trading mini account dengan jumlah transaksi sebesar 0.01 Lot. Hasil transaksi yang mendapatkan tingkat keuntungan dan kerugian yang tidak terkontrol, dimana hasil keuntungan terbesar sejumlah 1.70 Profit dan keuntungan terkecil 0.50 Profit,dan Kerugian terbesar dialami yaitu dengan -20.20 Profit dan terkecil dengan nilai 1.40 Profit. trader menggunakan trading manual ini rata-rata tanpa mematok harga dengan target Stop Loss dan Take Profit, sehingga hasil transaksi mengalami 75\% Loss.

\section{FX Clearing Group, Inc.}

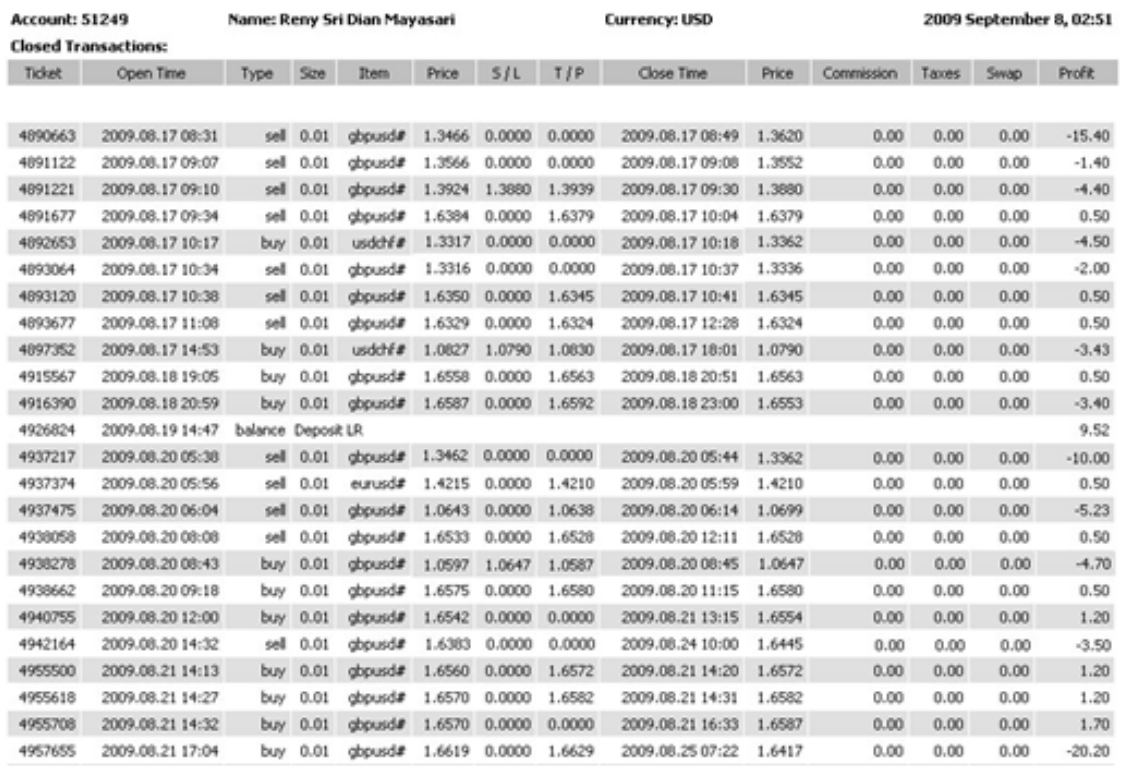

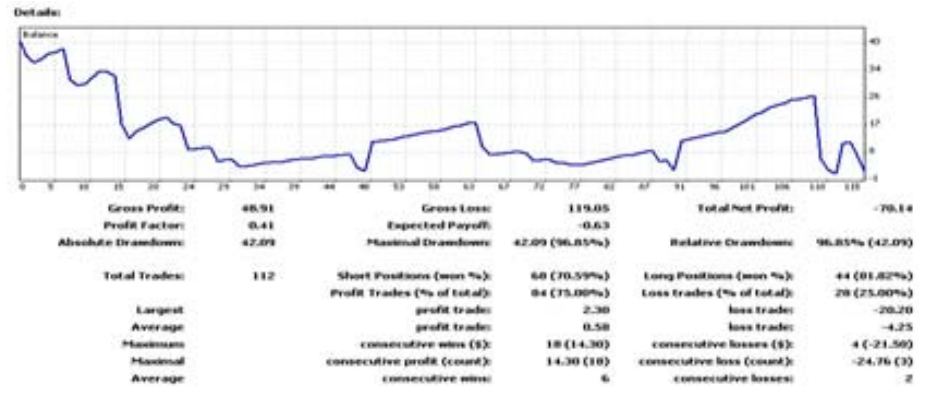

Gambar 12. Report Hasil Transaksi Manual Trading 


\section{* Report expert Trading.}

Hasil transaksi trader yang menggunakan Expert Advisors (Trisula EA), data diambil tanggal 17-08-20010 s/d 22-08-2010. Pada Gambar 13 dapat dijelaskan bahwa transaksi forex online trading menggunakan Expert Advisors mini account dengan jumlah transaksi sebesar 0.01 Lot. Hasil transaksi yang mendapatkan keuntungan rata-rata dengan nilai 5.50 dikarenakan Expert Advisors di setting dengan Take Profit sebesar 50pips, dan keuntungan terkecil pada nilai 1.00. Walaupun terlihat beberapa mengalami kerugian sebesar 7.50, kerugian ini dikarenakan Expert Advisors di Setting dengan StopLoss sebesat 75Pips. Apabila pada saat transaksi harga pasar makin melemah, Expert Advisors akan otomatis eksekusi untuk close order.
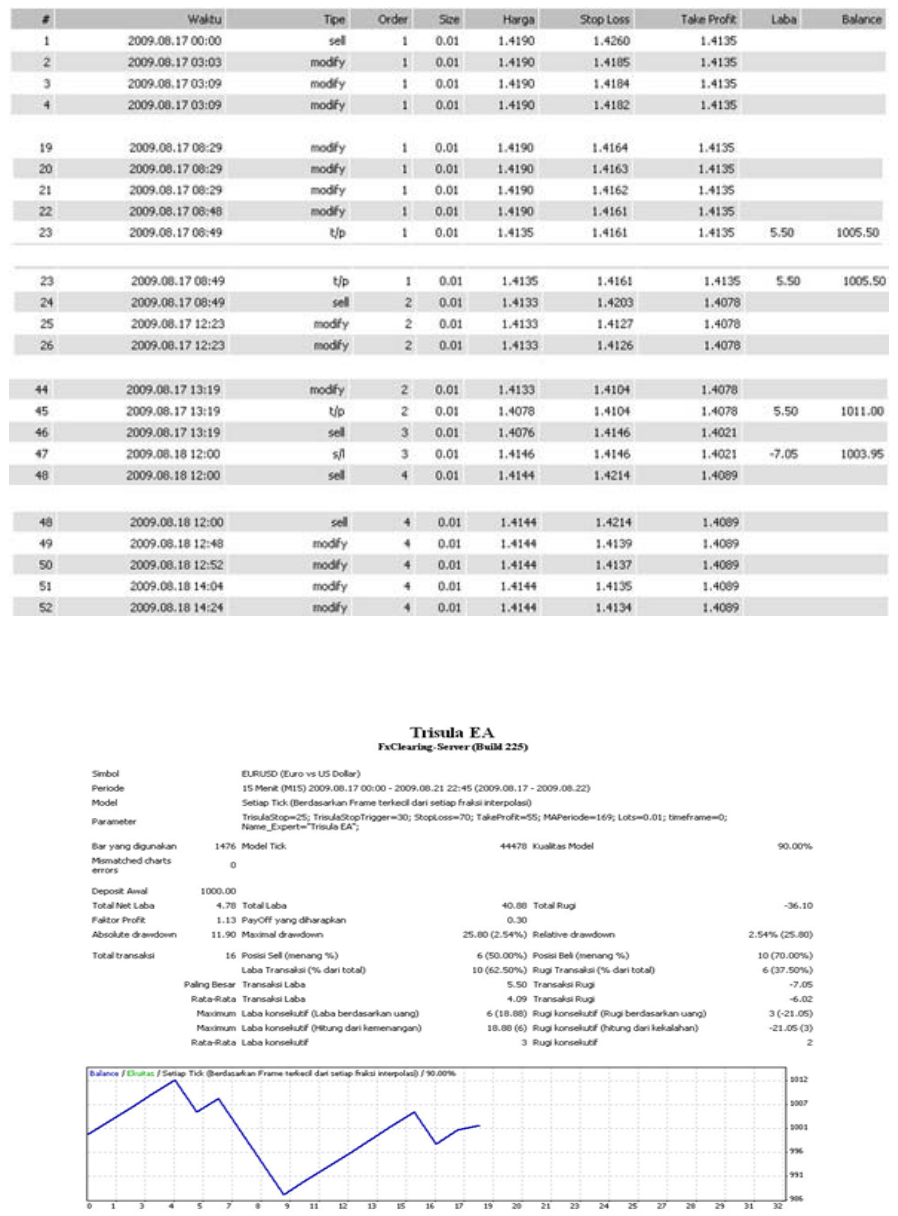

Gambar 13. Report Hasil Transaksi Expert Trading 
Dari analisa sistematika kinerja antara manual trading dan expert trading dapat dilihat dari Table 1 perbandingan antara manual trading dan expert trading.

Tabel 1. Tabel Perbandingan Manual Trading dan Expert Trading.

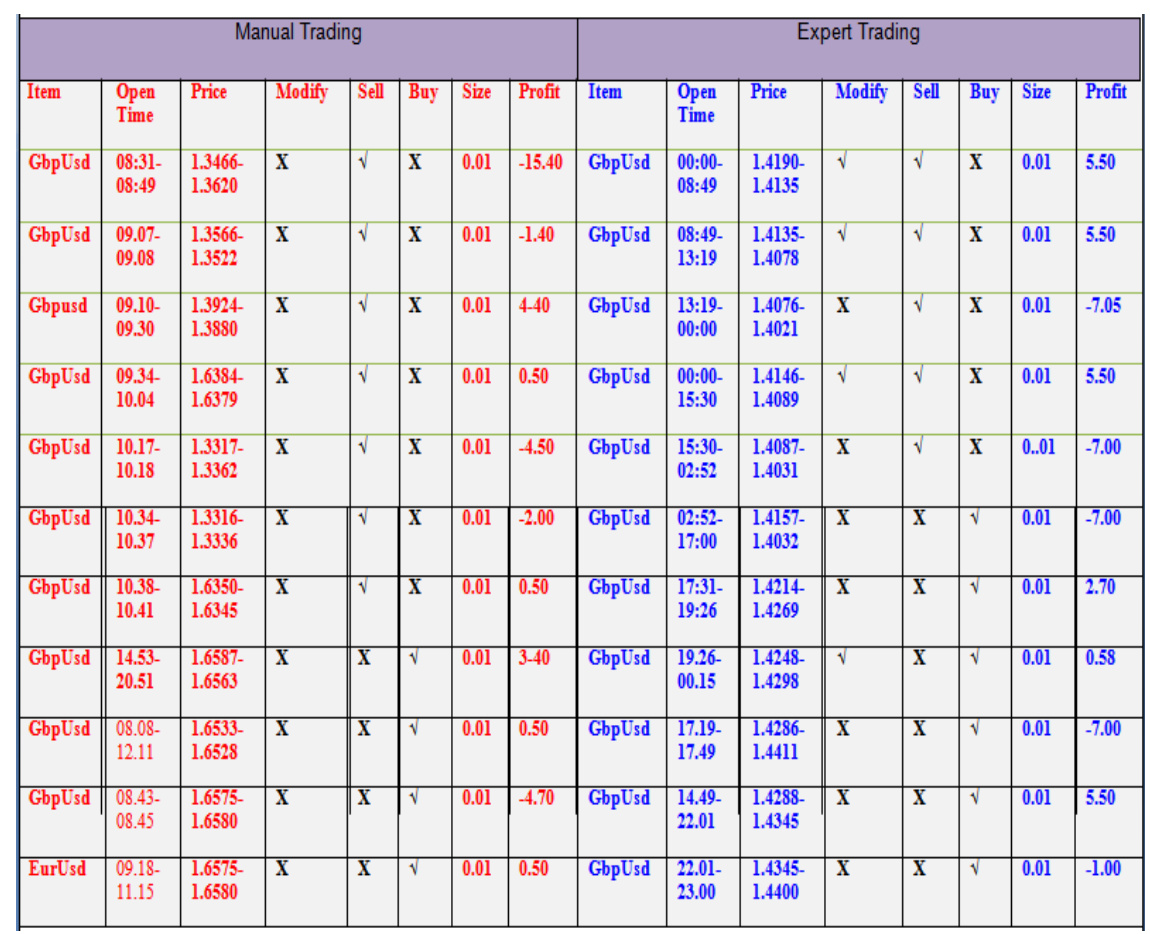

Dari tabel perbandingan antara maual trading dan expert trading dapat disimpulkan bahwa penggunaan expert trading lebih efektif dan konsisten dibandingkan dengan manual trading, dapat dilihat pada tabel 1 data diambil dari kisaran tanggal (17-08-2010 s/d 22-08-2010) selama satu minggu, dari hasil trading mengalami perbedaan untuk mengambil alih open order. Expert lebih fokus terhadap satu currency transaksi yaitu GbpUsd sedangkan manual trading sedikitnya memiliki tiga currency yaitu GbpUsd,UsdChf dan EurUsd, perbedaan lainnya terlihat pada pengambilah harga transaksi yang berbeda, dan waktu transaksi yann berbeda pula.

Dari hasil transkasi antara manual tarading dan expert trading, penggunaan expert trading lebih akurat dalam mendapatkan profit dibandingkan dengan menual trading. 


\section{KESIMPULAN}

Expert Advisors ini dibuat menggunakan bahasa pemrograman C di dalam flat form MetaQuotes Language Version 4 (MQL4). Dimana Expert Advisors ini biasa digunakan trader untuk bertransaksi atau trading secara otomatis.

Kelebihan dari penggunaan Expert Advisors adalah pengaturan yang mudah serta penggunaan yang mudah pula. Sehingga dengan adanya Expert Advisors tersebut Trader tidak harus memantau pergerakan forex secara nonstop seperti apa yang umumnya dilakukan trader jika memiliki floating loss. Expert Advisor dapat mengambil alih tugas dari trader dalam melakukan open order, close order yang telah profit, cut loss, ataupun money management. Expert Advisors ini juga memiliki kelebihan secara umum yaitu kemampuan untuk trading tanpa emosi. Kemampuan untuk trading secara otomatis. Dan Kemampuan untuk trading nonstop 24 jam.

Sedangkan kelemahan Expert Advisors ini adalah membutuhkan koneksi internet yang bagus dan tidak terputus-putus agar Expert Advisor dapat bekerja secara maksimal, Expert Advisors digunakan untuk trading secara online, Expert Advisors tidak akan berfungsi jika saat proses Expert Advisors sedang berjalan kemudian terjadi trouble pada koneksi internet atau bahkan mengalami kerusakan pada komputer atau trouble lainya seperti mengalami mati lampu,dan lain lain

Untuk mendapatkan hasil yang maksimal untuk mendapatkan Profit Trade disarankan hanya dipakai jika trend yang dihasilkan candle stick mengalami kenaikan, atau penurunan yang drastis dalam kurun waktu satu hari, dan tidak disarankan digunakan apabila trend tidak stabil .

\section{PUSTAKA}

1. Blanchette. Jasmin. dan Summerfield, M. 2008. C++ GUI Programmierung mit QT 4: Die offizielle Einführung. Pearson Education.

2. Budi,Prawira, 2005, Revolusi Investasi di era Cyber Dengan Forex OnLine Trading, Cemerlang Publishing.

3. Kristanto, A. 2003. Struktur Data Dengan C++. Yogyakarta : Graha Ilmu.

4. Susanto Iwan, 2007, 10 Langkah Memulai Forex Trading. Universitas Atma Jaya Yogyakarta.

5. Widoatmodjo, S, 2005. Forex on Line Trading. Elex Media Komputindo

6. Widoatmodjo, S, 2008, Forex Online Trading Trend Investasi Masa Kini Dengan Metatrader4. Elex Media Komputindo. 
7. http://www.autotradingfx.com/category/software-type/ebook

8. http://www.autotradingfx.com/forum/langkah2-sebelum-bikin-ea

9. http://www.abiyanto.net/?page_id=180

10. http://www.belajarforex.com/ index.php?option=com_fireboard\&Itemid=238\&id=12\&catid=1\&func=fb_pdf

11. http://www.belajarforexpro.com/panduanmt/panduanmt.pdf

12. http://www.belajarvalas.com/expertadvisor.php 